International Journal of Poultry Science 9 (4): 352-356, 2010

ISSN 1682-8356

(C) Asian Network for Scientific Information, 2010

\title{
Stochastic Estimation of Seroprevalence Against Ornithobacterium rhinotracheale and Avian Pneumovirus among Chickens in Argentina
}

\author{
J. Uriarte, K. Suzuki, J. Origlia, D. Gornatti, M. Píscopo, R. Cerda, M. Herrero, H. Marcantoni, \\ M.F. Unzaga, E. Spinsantti, F. Marino, M. Pecoraro, S. Corva and M. Petruccelli \\ Facultad de Ciencias Veterinarias, Universidad Nacional de La Plata, Argentina
}

\begin{abstract}
The objective of this study was to estimate the true prevalence of seropositive individual chicken against Ornithobacterium rhinotracheale and avian pneumovirus in Argentina, using the Rogan-Gladen estimator in combination with Bayesian inference. Chicken runs existed in 21 and 20 different towns in Buenos Aires and Entre Rios Provinces in Argentina for Ornithobacterium rhinotracheale and avian pneumovirus seroprevalence, respectively, were studied. Individual-chicken sera were analyzed using a commercial enzyme-linked immunosorbent assay. The 719 (for testing Ornithobacterium rhinotracheale) and 933 (for testing avian pneumovirus) chickens were investigated. The overall true seroprevalence was $62.6 \%$ [95\% Bayesian Credible Interval (BCl): $37.6-84.5 \%$ ] and $8.0 \%$ (95\% BCl: 1.4-18.5\%) against Ornithobacterium rhinotracheale and avian pneumovirus, respectively.
\end{abstract}

Key words: Bayesian inference, respiratory diseases, Rogan-Gladen estimator

\section{INTRODUCTION}

Prevalence is a scale of poultry disease frequency that concentrates on existing status rather than new events. Diagnostic tests are regularly used for prevalence studies and preferably, True Prevalence (TP) should be estimated from Apparent Prevalence (AP) by adjusting for test Sensitivity (Se) and Specificity (Sp) (Martin et al., 1987). In recent years, applications of Bayesian analytic methods (which are concerned with the consequences of modifying our previous beliefs as a result of receiving new data) for poultry-health prevalence survey data have increased. Use of Bayesian approaches gives a practical alternative for data analysis (Thrusfield, 2005; Vose, 2008).

Respiratory diseases have traditionally been a major concern in commercial poultry production. Various pathogens have been identified as causing respiratory disease, acting either in a primary or secondary role. Ornithobacterium rhinotracheale has been associated with respiratory signs and growth retardation, together with increased mortality, fibrinopurulent pneumonia and airsaculitis. Increases in medication costs, increases in condemnation rate, drops in egg production, reduction of eggshell quality and decreased hatchability have been reported (Bisgaard et al., 2008; Van Empel et al., 2008). Meanwhile, avian pneumoviruses can cause damage to the upper respiratory tract (trachea), such as, lack of cilia movement and/or cilia loss; damage that may lead to respiratory clinical signs such as coughing, sneezing, swollen head and more complicated respiratory problems (Cook, 2000; Gough, 2005). In South America, serological evidence of the Ornithobacterium rhinotracheale (Arns et al., 1998) and avian pneumovirus (Peres et al., 2006) infections in Brazil have been observed. To our knowledge, no report of these infections in Argentina has been publicized. The objective of this study was to estimate the TP of seropositive individual chicken against Ornithobacterium rhinotracheale and avian pneumovirus in Argentina, using the Rogan-Gladen estimator in combination with Bayesian inference.

\section{MATERIALS AND METHODS}

Study area: Argentina is the eighth-largest country in the world by land area (the second largest country in South America), constituted as a federation of 23 provinces and an autonomous capital city, Buenos Aires. It borders Paraguay and Bolivia to the north, Brazil and Uruguay to the northeast and Chile to the west and south. Argentina has a poultry population of 604 million, a poultry meat production of 1.2 million tonnes per year and a poultry egg production of 480,000 tonnes per year (FAO, 2009). The centre of the country including Buenos Aires and Entre Ríos Provinces (north of Buenos Aires Province) had the concentration of chicken population (about $85 \%$ of the total), because of in-and-around the big market Buenos Aires (FAO, 2009).

Sample collection: Chicken runs existed in 21 and 20 different towns in the study area for Ornithobacterium rhinotracheale and avian pneumovirus seroprevalence, respectively, were studied. None of the chickens had been vaccinated against Ornithobacterium rhinotracheale and avian pneumovirus prior to sampling. 
Int. J. Poult. Sci., 9 (4): 352-356, 2010

The required total sample size of 601 from a chicken population of 513 million was sufficient to produce a $95 \%$ confidence interval $(95 \% \mathrm{Cl})$ with a desired precision of $\pm 4 \%$ when the estimated AP was $50 \%$ (Hintze, 2008). The final sample size was determined by the accessible financial, human and material means. The field investigation was conducted between March 2007 and October 2008 for blood sample collections for each chicken.

Laboratory examinations: Blood samples collected were used for diagnostic investigations. Individualchicken sera were analyzed using a commercial Enzyme-linked Immunosorbent Assay (ELISA) for the detection of antibody against Ornithobacterium rhinotracheale (FlockChek@) Ornithobacterium rhinotracheale Antibody Test Kit, Dr Bommeli AG, a subsidiary of IDEXX Laboratories, Liebefeld-Bern, Switzerland) and avian pneumovirus (FlockChek@ Avian Pneumovirus Antibody Test Kit, Dr Bommeli AG, a subsidiary of IDEXX Laboratories, Liebefeld-Bern, Switerland), respectively. Positive and negative controls were included for each series of samples analyzed. Absorbance was read on an ELISA reader at $650 \mathrm{~nm}$. Based on the instruction manual of the ELISA kits, serum samples with Sample to Positive (S/P) ratios greater than 0.4 (titres greater than 844 ) for Ornithobacterium rhinotracheale and greater than 0.2 (titres larger than 396) for avian pneumovirus were considered seropositive, respectively.

Data analysis: Data were entered into a database using the Base in the OpenOffice.org software version 3.1.1 (Sun Microsystems, Santa Clara, CA, USA). Metaanalysis deals with the problem of reaching consensus on a particular question, using evidence from multiple independent studies (e.g. 21 Ornithobacterium rhinotracheale seroprevalence studies implemented in Argentina) (Sanchez et al., 2004; Dohoo et al., 2007). In this example, meta-analysis is based on the belief that the 21 studies that were actually done can be treated as a random sample from the population of studies. The purpose of each of these 21 studies was to estimate the overall true seroprevalence, each of the 21 studies had to draw samples randomly from its study population. Consequently, a meta-analysis is essentially a sample of samples. Each study population has a true (but unobserved) seroprevalence, which it estimated from a sample of subjects. Seroprevalence estimates based on the use of an imperfect test, which is a nature of ELISA tests, must be corrected to take account of test performance. Based on the ELISA sensitivity values (mode of $98 \%$ with $95 \%$ certain that $\mathrm{Se}>95 \%$ for Ornithobacterium rhinotracheale; mode of $98 \%$ with $95 \%$ certain that Se $>95 \%$ for avian pneumovirus) with the expert opinion and published ELISA specificity values (100\% and $98.4 \%)$ for Ornithobacterium rhinotracheale and avian pneumovirus, respectively, estimated TP of antibodies among study chicken at each town were calculated (IDEXX, 2002, 2004). TPs for each town were derived from the AP using the Rogan-Gladen estimator (Rogan and Gladen, 1978) and information about the Se and Sp:

$$
T P=(A P+S p-1) /(S e+S p-1)
$$

A hierarchical model, which is a type of meta-analyses mentioned above, consists of one layer of sampling above another. Two hierarchical models were made for monitoring infectious disease status or Ornithobacterium rhinotracheale and avian pneumovirus antibody seroprevalence in Argentina, respectively. Both models were fit using Bayesian methods which facilitate the estimation procedure for fitting complicated hierarchical models (Branscum et al., 2004; Papaspiliopoulos and Roberts, 2008). A Bayesian model was used to derive posterior Bayesian estimates (denoted $\mathrm{TP}_{\mathrm{B}}, \mathrm{Se}_{\mathrm{B}}$ and $\mathrm{Sp}_{\mathrm{B}}$, mentioned below) from prior distributions and the data from each town in this study. Consider estimation of the infection seroprevalence for a town where $y$ chicken tested positive out of $n$ chicken randomly selected. If the flock size $(\mathrm{N})$ is much larger than $n$, then the sampling distribution of $y$ is approximately binomial:

$$
y \mid T P_{B}, S e_{B}, S p_{B} \sim \operatorname{Binomial}(n, A P)
$$

Where $T P_{B}$ is the true seroprevalence of infection in the flock and $\mathrm{Se}_{\mathrm{B}}$ and $\mathrm{Sp}_{\mathrm{B}}$ are the sensitivity and specificity, respectively, of the diagnostic test applied to each chicken sampled and $A P=T P_{B}{ }^{*} S_{B}+\left(1-T P_{B}\right)\left(1-S p_{B}\right)$. The authors modeled uncertainty about the $S e_{B}$ and $S p_{B}$ of the diagnostic test using independent beta prior distributions (Vose, 2008):

$$
\begin{aligned}
& S e_{B} \sim \operatorname{Beta}(d+1, n-d+1) \\
& S p_{B} \sim \operatorname{Beta}(d+1, n-d+1)
\end{aligned}
$$

Where $d$ is the number of desired (positive or negative) outcomes and $n$ is the number of samples tested per town. These values were decided by using the expertspecified Se values and published $S p$ values for Ornithobacterium minotracheale and avian pneumovirus mentioned above. A beta distribution provides a flexible means of modeling uncertainty about parameters ranging from 0-1 (Baadsgaard and Jogensen, 2003).

At the second level of the hierarchy, the model was to assume that percentage of test positive were alike in some way. This was equal to specifying a random effects model for the true seroprevalence probability $p_{i}$ as follows. They were assumed to be drawn from a common Normal population distribution: 
Int. J. Poult. Sci., 9 (4): 352-356, 2010

$$
\begin{gathered}
\operatorname{logit}\left(p_{i}\right)=b_{i} \\
b_{1} \sim \operatorname{Nommal}(\mu, \tau)
\end{gathered}
$$

A standard non-informative prior is then specified for the population mean (logit) or probability of overall seroprevalence, $\mu$, with an alternative non-informative prior considered for the random effects variance (a uniform prior on the standard deviation), because of the absence of strong prior information:

$$
\begin{gathered}
\sigma \sim \text { Uniform }(0,100) \\
\tau=1 / \sigma^{2}
\end{gathered}
$$

The true seroprevalence probability and associated $95 \%$ Bayesian Credible Intervals (BCls) were computed via the Gibbs sampler, a Markov chain Monte Carlo (MCMC) technique, which was implemented using WinBUGS software (Lunn et al., 2000). The exponential of these true seroprevalence probabilities was taken to obtain overall seroprevalence estimates (Prev) and their 95\% BCls:

$$
\begin{aligned}
& \text { Prev }=\exp (\mu) /(1+\exp (\mu)) \\
& \mu \sim \text { Normal }(0.0,1.0 E-6)
\end{aligned}
$$

Results presented here were based on multiple runs of length 100,000 following a burn-in of 10,000 iterations to achieve convergence.

\section{RESULTS}

The 719 (for testing Ornithobacterium rhinotracheale) and 933 (for testing avian pneumovirus) chickens studied accounted for about $2^{*} 10^{-4} \%$ of the total chicken population in the study area. Table 1 shows the estimated seroprevalence against Ornithobacterium rhinotracheale and avian pneumovirus among the study chicken categorized by the study towns ( $n=21$ for Ornithobacterium rhinotracheale; $\mathrm{n}=20$ for avian pneumovirus). In the Ornithobacterium rhinotracheale study, the numbers of chicken sampled between the 21 study towns were varied from 3-180. Of all, 20 towns had AP of greater than $0 \%$, between 20 and $100 \%$. The AP of equal to $0 \%$ (Town $G$ ) was adjusted greater by Bayesian inference. All the point estimates of TP by Bayesian inference were greater than $0 \%$. All the APs were well within the Bayesian credibility intervals, except for the town with AP of equal to $0 \%$ mentioned above. The Bayesian posterior sampling means for the $\mathrm{Se}_{\mathrm{B}}$ and $S \mathrm{p}_{\mathrm{B}}$, estimated from the study, were $97.7 \%(95 \% \mathrm{BCl}$ : $95.1-99.3 \%)$ and $97.4 \%$ (95\% BCl: $90.5-99.9 \%)$, respectively. The overall true seroprevalence $\mathrm{TP}_{\mathrm{B}}$ was $62.6 \%(95 \% \mathrm{BCl}: 37.6-84.5 \%)$. Meanwhile, in the avian pneumovirus study, the numbers of chicken sampled between the 20 study towns were varied from 3-194. Of all, 13 towns had AP of greater than $0 \%$, between 2 and $44 \%$. The APs of equal to $0 \%$ (Town D, E, G, I, L, Q and W) were adjusted greater by Bayesian inference. All the point estimates of TP by Bayesian inference were greater than $0 \%$. All the APs were well within the Bayesian credibility intervals, except for the towns with $\mathrm{AP}$ of equal to $0 \%$ mentioned above. The Bayesian posterior sampling means for the $S e_{\mathrm{B}}$ and $S \mathrm{p}_{\mathrm{B}}$ estimated from the study, were $97.3 \%(95 \% \mathrm{BCl}$ : $94.3-$ $99.3 \%)$ and $98.4 \%(95 \% \mathrm{BCl}: 97.5-99.2 \%)$, respectively. The overall true seroprevalence $\mathrm{TP}_{\mathrm{B}}$ was $8.0 \%(95 \%$ BCl: 1.4-18.5\%).

\section{DISCUSSION}

This study represents the first moderate-scale seroepidemiological investigation on Ornithobacterium rhinotracheale and avian pneumovirus of chicken flocks in Argentina. The results of this study indicated that the seroprevalence of Ornithobacterium rhinotracheale and avian pneumovirus antibodies is relatively high in the flocks in the study area. However, several factors differed between studies, including study area, study period and sample size. These variations between study designs make it difficult to draw generalizable conclusions regarding the prevalence of any particular infectious diseases. Meta-analysis strengthens the power of individual and relatively small studies by compiling results from independent studies (Dohoo et al., 2003). The strengthened power leads to a higher precision of the estimates, by that means decreasing the variance and more accurately pointing out notable results. Adjusted outcomes are required for precise comparison of seroprevalence estimates. One of the aims of the present study was to illustrate how a hierarchical modeling approach permits the dependable estimation of the uncertainty corresponding an individual study's effect on outcome. The advantage of the approach taken in the study was that outcome data from all studies could be incorporated in one coherent inference framework, including small samples. The hierarchical model data across all field investigations to calculate the prevalence and $\mathrm{BCls}$ thus making comparative assessment more robust and more reliable (Lunn et al., 2000; Dohoo et al., 2003). The methodology was useful for obtaining estimates of Ornithobacterium rhinotracheale and avian pneumovirus prevalence and for establishing prevalence distributions which could be used as input parameters in risk assessment and decision models. The analyses provide some guidelines for use when interpreting Ornithobacterium rhinotracheale and avian pneumovirus prevalence results and when comparing results from studies using different study designs (study area and study period particularly). 
Int. J. Poult. Sci., 9 (4): 352-356, 2010

Table 1: Estimated seroprevalence against Omithobacterium rhinotracheale and avian pneumovirus among chickens in Buenos Aires y Entre Ríos Provinces in Argentina

\begin{tabular}{|c|c|c|c|c|c|c|c|c|c|c|}
\hline \multirow[b]{3}{*}{ Town ID } & \multicolumn{5}{|c|}{ Omähobacterium minotracheale } & \multicolumn{5}{|c|}{ Avian pneumovirus } \\
\hline & \multirow[b]{2}{*}{$\mathrm{n}$} & \multirow[b]{2}{*}{$\mathrm{AP}(\%)$} & \multirow[b]{2}{*}{ TP (\%) } & \multicolumn{2}{|c|}{$95 \% \mathrm{BCl}(\%)$} & \multirow[b]{2}{*}{$\mathrm{n}$} & \multirow{2}{*}{$\begin{array}{l}\text { AP } \\
(\%)\end{array}$} & \multirow{2}{*}{$\begin{array}{l}\text { TP } \\
(\%)\end{array}$} & \multicolumn{2}{|c|}{$95 \% \mathrm{BCl}(\%)$} \\
\hline & & & & Lower & Upper & & & & Lower & Upper \\
\hline $\bar{A}$ & 15 & 100 & 95 & 81 & 100 & - & - & - & - & - \\
\hline B & 12 & 67 & 67 & 39 & 90 & 12 & 17 & 13 & 0.5 & 37 \\
\hline c & 76 & 25 & 24 & 13 & 35 & 76 & 37 & 36 & 25 & 48 \\
\hline D & 50 & 30 & 29 & 16 & 44 & 36 & 0 & 2 & 0.01 & 7 \\
\hline $\mathrm{E}$ & 4 & 50 & 52 & 11 & 91 & 4 & 0 & 6 & 0.02 & 31 \\
\hline $\mathrm{F}$ & 180 & 26 & 24 & 16 & 32 & 194 & 2 & 0.8 & 0.01 & 3 \\
\hline $\mathrm{G}$ & 16 & 0 & 6 & 0.1 & 20 & 16 & 0 & 3 & 0.01 & 12 \\
\hline $\mathrm{H}$ & 58 & 48 & 48 & 34 & 62 & 58 & 16 & 14 & 6 & 25 \\
\hline I & 3 & 67 & 66 & 18 & 98 & 3 & 0 & 7 & 0.02 & 38 \\
\hline$J$ & 5 & 60 & 61 & 21 & 94 & 5 & 20 & 15 & 0.1 & 50 \\
\hline $\mathrm{K}$ & 23 & 96 & 94 & 81 & 100 & - & - & - & - & - \\
\hline L & 5 & 60 & 61 & 21 & 94 & 5 & 0 & 6 & 0.02 & 28 \\
\hline$M$ & 15 & 100 & 95 & 81 & 100 & 30 & 40 & 38 & 22 & 56 \\
\hline$N$ & 37 & 49 & 49 & 32 & 65 & 37 & 43 & 42 & 26 & 59 \\
\hline 0 & 5 & 20 & 27 & 16 & 66 & - & - & - & - & - \\
\hline$P$ & 5 & 40 & 43 & 79 & 83 & - & - & - & - & - \\
\hline$Q$ & 34 & 35 & 35 & 19 & 53 & 34 & 0 & 2 & 0.01 & 7 \\
\hline $\mathrm{R}$ & 43 & 88 & 90 & 78 & 98 & 86 & 14 & 13 & 6 & 21 \\
\hline$s$ & 43 & 68 & 66 & 50 & 80 & 43 & 26 & 24 & 12 & 38 \\
\hline$T$ & 57 & 60 & 60 & 46 & 73 & - & - & - & - & - \\
\hline u & 33 & 97 & 96 & 87 & 100 & 18 & 28 & 25 & 8 & 47 \\
\hline v & - & - & - & - & - & 7 & 43 & 36 & 7 & 71 \\
\hline W & - & - & - & - & - & 20 & 0 & 2 & 0.01 & 11 \\
\hline$x$ & - & - & - & - & - & 138 & 44 & 44 & 35 & 53 \\
\hline$Y$ & - & - & - & - & - & 111 & 5 & 4 & 0.3 & 9 \\
\hline
\end{tabular}

$\mathrm{n}$; Number of Chickens Sampled, AP; Apparent Seroprevalence, TP; True Seroprevalence, $95 \%$ BCl; $95 \%$ Bayesian Credible Interval

\section{ACKNOWLEDGEMENTS}

This study was carried out as part of the project for the capacity development for improvement of livestock hygiene in the southern part of South America through regional cooperation [commonly known as: Proyecto de desarrollo profesional continuo para los veterinarios del Sur (PROVETSUR)], funded by the Japan International Cooperation Agency.

\section{REFERENCES}

Arns, C.W., H.M. Hafez, T. Yano, M.C.G.B. Monteiro, M. Celestino Alves, H.G. Domingues and L.T. Coswig, 1998. Ornithobacterium rhinotracheale: Detecção sorológica em aves matrizes e frangos de corte. In: Proceedings of Conferência Apinco 1998, São Paulo, pp: 55 (in Portuguese).

Baadsgaard, N.P. and E. Jogensen, 2003. A Bayesian approach to the accuracy of clinical observations. Prev. Vet. Med., 59: 189-206.

Bisgaard, M., A.M. Bojesen, J.P. Christensen, P. Mark, F.M. Paul, M.B. Janet and J.A. Dennis, 2008. Infections Caused by Species of Pasteurellaceae, Ornithobacterium and Riemerella: an Introduction. Poultry Diseases, 6th Edn., W.B. Saunders, Edinburgh, pp: 146-148.
Branscum, A.J., I.A. Gardner and W.O. Johnson, 2004. Bayesian modeling of animal- and herd-level prevalences. Prev. Vet. Med., 66: 101-112.

Cook, J.K.A., 2000. Avian pneumovirus infections of turkeys and chickens. Vet. J., 160: 118-125.

Dohoo, I., W. Martin and H. Stryhn, 2003. Veterinary Epidemiologic Research. AVC, Prince Edward Island, pp: 706.

Dohoo, I., H. Stryhn and J. Sanchez, 2007. Evaluation of underlying risk as a source of heterogeneity in meta-analyses: A simulation study of Bayesian and frequentist implementations of three models. Prev. Vet. Med., 81: 38-55.

FAO, 2009. FAOSTAT. Rome. Available from: http://faostat.fao.org/.

Gough, R.E., 2005. Poultry: Avian Pneumovirus. In: The Merck Veterinary Manual, Kahn, C.M. (Ed.). 9th Edn., Merck and Co., Whitehouse Station, pp: 2299-2300.

Hintze, J., 2008. PASS 2008 software. NCSS, Kaysville, UT.

IDEXX, 2002. IDEXX ORT Test Kit detects all serotypes in chicken and turkey serum. Available from: http://mww.idexx.com/pubwebresources/pdf/en_us/ livestock-poultry/0962896.pdf. 
IDEXX, 2004. Effective tool for monitoring avian pneumovirus in chicken and turkey flocks. Available from: http://mww.idexx.com/pubwebresources/pdf/ en_us/livestock-poultry/6478800m.pdf.

Lunn, D.J., A. Thomas, N. Best and D. Spiegelhalter, 2000. WinBUGS - a Bayesian modelling framework: concepts, structure and extensibility. Stat. Comput., 10: 325-337.

Martin, S.W., A.H. Meek and P. Willeberg, 1987. Veterinary Epidemiology. Iowa State University Press, Ames, pp: 343.

Papaspiliopoulos, 0 . and $G$. Roberts, 2008. Stability of the Gibbs sampler for Bayesian hierarchical models. Ann. Stat., 36: 95-117.

Peres, M.F., A.S. Carrijo, J.A. Higa and J.M. De Oliveira, 2006. Serological evidence of avian pneumovirus infections in broiler flocks in counties of Mato Grosso do Sul. Pesqui. Vet. Brasil., 26: 254-258 (in Portuguese).
Rogan, W.J. and B. Gladen, 1978. Estimating prevalence from results of a screening-test. Am. J. Epidemiol., 107: 71-76.

Sanchez, J., I. Dohoo, J. Carrier and L. DesCôeaux, 2004. A meta-analysis of the milk-production response after anthelmintic treatment in naturally infected adult dairy cows. Prev. Vet. Med., 63: 237256.

Thrusfield, M., 2005. Veterinary Epidemiology. 3rd Edn., Wiley-Blackwell, Oxford, pp: 584.

Van Empel, P., P. Mark, F.M. Paul, M.B. Janet and J.A. Dennis, 2008. Ornithobacterium rhinotracheale. Poultry Diseases. 6th Edn., W.B. Saunders, Edinburgh, pp: 164-171.

Vose, D., 2008. Risk analysis: A quantitative guide, 3rd Edn., Wiley, Chichester, pp: 752. 